\title{
A Invasão Hermenêutica da Filosofia e da Economia*
}

\author{
Murray N. Rothbard**
}

\begin{abstract}
Resumo: O presente artigo critica a filosofia hermenêutica por sua obscuridade e irracionalidade. Após analisar a evolução da metodologia da Economia de Robbins,e chegar até Friedman, Rothbard argumenta que o fracasso do programa instrumentista para a Economia não deve convidar à aceitação da abordagem retórica. $\mathrm{O}$ artigo termina com a rejeição do uso de certas idéias hermenêuticas defendidas por alguns autores austríacos como Lavoie e Ebeling.
\end{abstract}

Palavras-Chave: Filosofia, Economia, Hermenêutica, Desconstrucionismo, Incompreensibilidade, Coletivismo, Niilismo.

\section{The Hermeneutical Invasion of Philosophy and Economics}

\begin{abstract}
The present article criticizes hermeneutic Philosophy for its obscurity and irrationality. After reviewing the evolution of the methodology of Economics from Robbins to Friedman, Rothbard argues that the failure of instrumentalist programme for Economics should not invite the acceptance of its rhetorical approach to Economics. The article ends with the rejection of some hermeneutical ideas usage by some Austrian authors, such as Lavoie and Ebeling.
\end{abstract}

Keywords: Philosophy, Economy, Hermeneutics, Incomprehensibility, Collectivism, Nihilism.

Classificação JEL: B41

\footnotetext{
* O presente artigo foi publicado originariamente em Review of Austrian Economics, 3 (1989): 45-59. O artigo foi adaptado de um documento distribuído em uma conferência sobre Tendências nas Ciências Sociais, sediada pelo London Academic and Cultural Resources Fund e pelo Instituto de Filosofia da Universidade Jaguelônica de Cracóvia, na Polônia, em abril de 1987. A tradução utilizou o texto publicado na seguinte edição: ROTHBARD, Murray N. The Hermeneutical Invasion of Philosophy and Economics. In: Economic Controversies. Auburn: Ludwig von Mises Institute, 2011. p. 119-36.

Traduzido do original em inglês para o português por William Bottazzini.

${ }^{*}$ Murray N. Rothbard nasceu em 2 de março de 1926, no Bronx, em Nova York. Graduou-se em Matemática, em 1945, na Columbia University, por onde também recebeu, em 1956, o título de Doutor em Economia. Lecionou no Brooklyn Polytechnic Institute, de 1964 a 1986, e na escola de negócios da University of Nevada, em Las Vegas, de 1986 até a morte, em 1995. Rothbard foi o fundador e principal teórico do anarco-capitalismo, um firme defensor do revisionismo histórico, e uma figura central no movimento libertário norte-americano do século XX. É autor de mais de vinte livros, dentre os quais se destacam o tratado de economia Man, Economy, and State e Governo e Mercado (Instituto Ludwig von Mises Brasil, 2012). Faleceu no dia 7 de janeiro de $1995 \mathrm{em}$ Nova York, nos Estados Unidos.
} 
Nos últimos anos, os economistas invadiram outras disciplinas intelectuais e, com o nome duvidoso de "ciência", empregaram, de forma assombrosa, hipóteses exageradamente simplificadas, a fim de tirar conclusões generalizantes e provocadoras sobre áreas das quais conhecem muito pouco. Essa é uma forma moderna de "imperialismo econômico" no âmbito do intelecto. $\mathrm{O}$ viés desse imperialismo econômico é quase sempre quantitativo e implicitamente benthamita, em que a poesia e o jogo de pushpin ${ }^{1}$ são reduzidos a um mesmo nível ${ }^{2}$, o que justifica bastante a troça de Oscar Wilde (1854-1900) sobre os cínicos, quando disse que eles (os economistas) "sabem o preço de tudo, mas não sabem o valor de nada"3. $\mathrm{O}$ resultado desse imperialismo econômico é particularmente ridículo nas áreas do sexo, da família e da educação.

Portanto, por que este autor, que não é benthamita, tem a temeridade de abordar um campo tão arcano, abstruso, metafísico e

1 O pushpin é um jogo infantil de tabuleiro muito popular nos países anglo-saxões desde o século XVI, inicialmente jogado com alfinetes. No século XIX foi imortalizado nas menções feitas por Jeremy Bentham (1748-1832) e John Stuart Mill (1806-1873) como forma de diversão relativamente inútil. Possui vários formatos de tabuleiro e algumas variações escocesas e irlandesas. Os pinos ou bolinhas são presos ao tabuleiro e dispostos em campos adversários. A regra básica é eliminar o maior número de pinos do adversário fazendo o seu pino saltar sobre a peça inimiga, eliminando-a. No Brasil temos uma versão desse jogo chamada "Resta um". (N. do E.)

${ }^{2} \mathrm{Na}$ obra The Rationale of Reward [A Análise Racional da Recompensa], de 1830, Jeremy Bentham afirma que "Preconceitos à parte, o jogo de pushpin equiparase às artes da música e da poesia" [BENTHAM, Jeremy, The Rationale of Reward. London: Robert Heward, 1830. p. 206]. John Stuart Mill, no famoso ensaio sobre Bentham (1838) em que apresenta várias discordâncias do mentor, cita erroneamente a passagem e afirma que Bentham dissera que "pushpin é tão bom quanto poesia" [MILL, J. S. "Bentham". In: Dissertations and Discussions. London: Parker, 1859. Vol. I, p. 389]. Muitas vezes, a frase de Stuart Mill é citada como se fosse a afirmação original de Bentham. (N. do E.)

3 WILDE, Oscar. Lady Windermere's Fan, A Play About a Good Woman. Ed. David Price. London: Methuen \& Co. Ltd., 1917. Ato III. aparentemente sem relação com a economia como a hermenêutica? Aqui o meu arrazoado é aquele sempre legítimo de autodefesa. Uma disciplina após outra, da literatura à teoria política, à filosofia e à história, tem sido invadida por um bando arrogante de hermeneutas, e neste momento até mesmo a economia está sitiada. Por isso este artigo está na posição de contra-ataque.

Para começar, a definição do dicionário para "hermenêutica" é a velha "disciplina de interpretação da Bíblia". Até a década de vinte ou trinta do século XX, com efeito, a hermenêutica estava restrita a teólogos e a departamentos de religião. Mas as coisas mudaram com o advento da turva doutrina alemã de Martin Heidegger (1889-1976), o fundador da hermenêutica moderna. Com a morte de Heidegger, a sucessão apostólica de chefe do movimento hermenêutico foi passada para o seu aluno, Hans-Georg Gadamer (1900-2002), que ainda exerce essa função.

O maior sucesso do movimento hermenêutico foi alcançado nas últimas décadas, começando no movimento de "desconstrucionismo" na crítica literária, que está intimamente relacionado com o movimento hermenêutico. Capitaneado pelos teóricos franceses Michel Foucault (1926-1984), Paul Ricoeur (1913-2005) e Jacques Derrida (1930-2004), o desconstrucionismo no hemisfério ocidental é liderado pelo influente departamento inglês da Yale University, de onde se espalhou para conquistar a maior parte dos departamentos de literatura inglesa dos Estados Unidos e do Canadá. A mensagem essencial do desconstrucionismo e da hermenêutica pode ser resumida de diversas maneiras: niilismo, relativismo e solipsismo. Isto é, não há verdade absoluta ou, se houver, nunca conseguiremos descobri-la. Estando cada pessoa presa a suas próprias opiniões subjetivas, a seus próprios sentimentos, a sua própria história, e assim por diante, não há nenhum método para descobrir a verdade objetiva. Na literatura, o procedimento mais elementar de crítica literária (ou seja, tentar identificar o que certo autor quis dizer) se torna impossível. A comu- 
nicação entre o escritor e o leitor se torna, da mesma forma, irrecuperável; ademais, não somente o leitor nunca consegue descobrir o que um autor quis dizer, mas também o autor não sabe ou não compreende o que ele mesmo quis dizer, tão fragmentado, confuso e condicionado é cada indivíduo em particular. Assim, visto que é impossível identificar o que William Shakespeare (1564-1616), Joseph Conrad (1857-1924), Platão (427-357 a.C.), Aristóteles (384-322 a.C.) ou Nicolau Maquiavel (1469-1527) quis dizer, para que serve ler ou escrever uma crítica literária ou filosófica?

Essa é uma pergunta interessante à qual os desconstrutivistas e outros hermeneutas não podem, obviamente, responder. Pelo que eles mesmos confessam, é impossível para desconstrutivistas compreender textos literários, ou, por exemplo, para Gadamer compreender Aristóteles, a respeito de quem, não obstante, já escreveu rios de tinta. Conforme assinalou o filósofo inglês Jonathan Barnes em sua brilhante e engenhosa crítica da hermenêutica, Gadamer, não tendo nada que dizer de Aristóteles ou de seus trabalhos, está limitado a relatar as suas próprias meditações subjetivas - uma espécie de relato prolongado sobre "o que Aristóteles significa para mim". Deixando de lado o problema hermenêutico da possibilidade ou impossibilidade de Gadamer saber até mesmo o que Aristóteles quis dizer, trazemos o problema de volta para outro patamar. E este é: por que no mundo alguém, exceto Gadamer, exceto possivelmente a sua mãe ou esposa, estaria minimamente interessado no problema do significado de Aristóteles para ele? E mesmo na hipótese improvável de que estivéssemos interessados nesse problema que abala as estruturas da Terra, estaríamos impossibilitados, com base nos princípios hermenêuticos, de entender a resposta de Gadamer.

${ }^{4}$ BARNES, Jonathan. A Kind of Integrity Review of HansGeorg Gadamer. In: Philosophical Apprenticeships. Cambridge: MIT Press, 1985; GADAMER, HansGeorg. The Idea of the Good in Platonic-Aristotelian Philosophy. New Haven: Yale University Press, 1986; London Review of Books, (November 6, 1986): 12-13.
A desconstrução e a hermenêutica claramente refutam a si mesmas em vários níveis. Se não podemos compreender o significado de nenhum texto, por que nos damos ao trabalho de tentar entender ou de levar a sério trabalhos ou doutrinas de autores que proclamam agressivamente a sua própria incompreensibilidade?

\section{I - INCOMPREENSIBILIDADE}

Com efeito, um ponto crucial com respeito aos hermeneutas é que, para eles, a incompreensibilidade é uma profecia autorrealizável. Como me disse um colega com pesar: "Sobre hermenêutica, li tudo aquilo em que pude pôr as mãos e ainda não tenho uma compreensão melhor do que quando comecei". Mesmo em uma profissão - filosofia - que não é exatamente famosa por sua clareza ou lucidez, uma das qualidades mais notáveis dos hermeneutas é o seu estilo horrendo e incomparavelmente obscuro. Estalactites ou estalagmites de jargões se empilham uns sobre os outros em um verdadeiro sambaqui de prosa estupeficante e sem sentido. Os hermeneutas parecem ser incapazes de escrever uma frase em inglês, ou mesmo alemã, que seja clara. Críticos da hermenêutica - como Johnathan Barnes ou David Gordon ${ }^{5}$ - são compreensivelmente compelidos à sátira quando expõem e citam tratados hermenêuticos e em seguida "os traduzem" para um inglês simples, onde invariavelmente se mostram banais ou idiotas.

No início, acreditava que esses hermeneutas alemães estavam somente mal servidos de tradutores para o inglês. Mas meus amigos alemães me garantem que Heidegger, Gadamer e outros são igualmente ininteligíveis no original. Na verdade, em um ensaio recentemente traduzido, Eric Voegelin (1901-1985), um filósofo normalmente não

${ }^{5}$ BARNES. A Kind of Integrity Review of HansGeorg Gadamer. Ver, também: GORDON, David. Hermeneutics versus Austrian Economics. Auburn: Ludwig von Mises Institute, 1986. 
dado a cintilar humor, foi levado a ridicularizar a linguagem de Heidegger. Referindo-se à obra-prima de Heidegger, Sein und Zeit (Ser e Tempo), Voegelin menciona a repetição sem sentido, mas insistente, de um verdadeiro dicionário filosófico de frases como Anwesen des Anwesenden ("a presença daquilo que está presente"), Dingen des Dings ("a reificação da coisa"), Nichten des Nichts ("a nadificação do nada") e, finalmente, o zeigenden Zeichen des Zeigzeugs ("o sinal que mostra o instrumento-sinalizador"), sendo todas elas projetadas, diz Voegelin, para alvoroçar o leitor "em um estado alienante da realidade e de delírio linguístico"6.

A respeito de Gadamer e dos hermeneutas, Jonathan Barnes escreve:

Quais são, pois, as características próprias da filosofia hermenêutica? Seus inimigos irão arremeter com adjetivos como vazia, insípida, delirante, confusa, retórica. O próprio Gadamer conta uma história incomum. No fim de um seminário sobre [Tommaso de Vio (1469-1534), o cardeal] Caetano, Heidegger certa vez assustou a sua dedicada audiência ao fazer a seguinte pergunta: "Que é ser?". "Nós nos sentamos ali com os olhares fixos e balançamos a nossa cabeça diante do absurdo da pergunta." Muito correto também, dizem os inimigos dos hermeneutas: a pergunta é perfeitamente absurda. Mas Gadamer tem somente uma frágil noção do absurdo e seus leitores devem reagir como ele certa vez - mas infelizmente uma só vez - reagiu diante de Heidegger.

Barnes continua e diz que Gadamer admite "que o seu pensamento, por vezes, tem sido menos do que translúcido." Mais adiante, cita o que disse Gadamer:

É certo que por vezes falei de um modo exageradamente difícil para os meus alunos e coloquei muitas complicações na minha linha de raciocínio. Mesmo antes, os meus amigos tinham inventado uma nova

\footnotetext{
${ }^{6}$ VOEGELIN, Eric. The German University and the Order of German Society: A Reconsideration of the Nazi Era. Intercollegiate Review, 20 (Spring/Summer, 1985): p. 11.
}

medida científica, o "Gad", que designava uma medida estabelecida de complicações desnecessárias.

\section{Barnes acrescenta que:}

Alguns podem preferir a essa historieta de autoglória uma observação que Gadamer faz de si mesmo quando mais jovem: "Apesar de meu título de doutor, eu ainda era um garoto de vinte e dois anos que pensava com um juízo bastante obscuro e que ainda não sabia realmente o que estava acontecendo".

Barnes conclui: "Será que este garoto cresceu algum dia?"

Neste ponto, podemos citar Karl Popper (1902-1994) a respeito de G. W. F. Hegel (17701831), que é considerado, com Friedrich Schleiermacher (1768-1834), ao menos um bisavô da hermenêutica. Aquilo que falta a Popper no quesito de dom para a sátira, ele o compensa na veemência do desprezo que amontoa sobre a legião de seus inimigos filosóficos, sejam reais ou imaginários. Depois de denunciar a "extravagante algaravia" e as "modas imbecis", Popper cita, com um deleite evidente, o ataque a Hegel de um contemporâneo dele, Arthur Schopenhauer (1788-1860):

Um cabeça de vento, insípido, nauseante e charlatão iletrado, que atingiu o pináculo da audácia rabiscando e oferecendo as mais loucas e desconcertantes tolices. Essas tolices foram estrondosamente proclamadas como sabedoria imortal por seguidores mercenários e prontamente aceitas como tal por todos os tolos que, desta forma, uniram-se em um coro tão perfeito de admiração como nunca se viu antes ${ }^{8}$.

Por que essa enorme aclamação e influência exercida por tolices desconcertantes? Além de notar o seu estabelecimento nos interesses do Estado prussiano, Popper oferece a seguinte explicação:

\footnotetext{
${ }^{7}$ BARNES. A Kind of Integrity Review of Hans-Georg Gadamer. p. 13.

${ }^{8}$ POPPER, Karl R. The Open Society and its Enemies. New York: Harper and Row, $4^{\text {th }}$ ed., 1962. Vol. 2, p. 33.
} 
Por alguma razão, os filósofos mantiveram em torno de si mesmos, mesmo hoje, algo da aura do mágico. A filosofia é considerada algo estranho e abstruso, que lida com mistérios com os quais lida a religião, mas não de um modo que pode ser "revelado para criancinhas" ou para pessoas comuns; considera-se que ela seja demasiado profunda para isso e que seja a religião e a teologia dos intelectuais, dos letrados e sábios?.

Para uma última citação da incompreensibilidade da hermenêutica, voltemo-nos para a espirituosa e devastadora demolição que $\mathrm{H}$. L. Mencken (1880-1956) fez de Thorstein Veblen (1857-1929), outro proto-hermeneuta e oponente institucionalista da ideia de lei econômica. Ao longo de um ensaio que destacava a "tradução" para o inglês da prosa indecifrável de Veblen, Mencken escreveu que o que era realmente notável nas ideias de Veblen:

Era a maneira estonteantemente grandiosa e excessivamente intrincada de sua colocação, o quase inacreditável fastio e a pretensão da prosa do talentoso professor titular, seu talento sem precedentes para não dizer nada ainda que de forma augusta e heroica. [...] Ouso dizer que Marx havia dito boa parte disso antes dele, e aquilo que deixou passar foi repetido por diversas vezes por seus herdeiros e representantes. Mas Marx, nesse assunto, trabalhou sob uma limitação técnica: escrevia em alemão, uma língua que entendia de verdade. O prof. Veblen não se submeteu a essa desvantagem. Embora tenha nascido, creio, nos Estados Unidos, e residido aqui por toda a sua vida, ele conseguiu o efeito, talvez sem empregar os meios, de pensar em alguma língua sobrenatural ou estrangeira - digamos suaíli, sumério ou búlgaro antigo - para, depois, cravar os seus pensamentos em um inglês copioso e incerto, porém não aprendido nos livros. O resultado foi um estilo que afetava os centros cerebrais mais elevados como um fluxo constante de trens subterrâneos. O segundo resultado foi uma espécie de torpor perplexo dos sentidos, como diante de uma maravilha fabulosa e sobrenatural.

${ }^{9}$ Idem, Ibidem., p. 30.
E o terceiro resultado, se eu não estiver enganado, foi a fama do professor como um grande pensador ${ }^{10}$.

\section{II - Coletivismo}

Karl Marx (1818-1883), com efeito, tem sido saudado pelos hermeneutas como um dos avôs do movimento. Em 1985, por exemplo, no encontro anual da Western Political Science Association (WPSA) [Associação de Ciência Política da Costa Oeste] em Las Vegas, praticamente todos os trabalhos apresentados sobre teoria política eram hermenêuticos. Um título paradigmático seria: "A vida política como um texto: hermenêutica e interpretação em Marx, Heidegger, Gadamer e Foucault" - substitua livremente tais nomes por Ricoeur e Derrida, com uma reverência eventual a Jürgen Habermas.

Não creio que seja um acidente o fato de Marx ser considerado um dos grandes hermeneutas. Este século assistiu a uma série de reveses devastadores para o marxismo, para as suas pretensões de "verdade científica" e para as suas proposições teóricas, bem como para as suas afirmações empíricas e previsões. Se o marxismo foi peneirado tanto na teoria quanto na prática, então em que os seus seguidores podem sustentar-se? Parece-me que a hermenêutica se ajusta bem em um era que podemos, seguindo uma estratégia marxista sobre o capitalismo, chamar de "marxismo tardio" ou marxismo em declínio. O marxismo não é verdadeiro nem é ciência. Então é o quê? Os hermeneutas nos dizem que nada é objetivamente verdadeiro e que, portanto, todas as opiniões e proposições são subjetivas, relativas ao capricho e aos sentimentos de cada indivíduo. Então por que os anseios marxistas não deveriam ser igualmente tão válidos quanto os de qualquer outra pessoa? Pelas vias da hermenêutica, esses anseios não podem ser submetidos à refutação. E, visto que não há realidade objetiva e que a reali-

${ }^{10}$ MENCKEN, H. L. Professor Veblen. In: A Mencken Chrestomathy. New York: Alfred A. Knopf, 1949. p. 270. 
dade é criada pelas interpretações subjetivas de cada homem, todos os problemas sociais se reduzem a gostos pessoais e irracionais. Se, então, os marxistas hermenêuticos acham que o capitalismo é feio e desagradável e que o socialismo é lindo, por que não deveriam tentar colocar as suas preferências estéticas pessoais em prática? Se sentem que o socialismo é lindo, o que pode detê-los, especialmente diante do fato de que não há leis de economia ou verdades de filosofia política que possam colocar-lhes obstáculos no caminho?

Não é por acaso que, com exceção de um punhado de economistas contemporâneos, que serão tratados de modo mais detalhado posteriormente, cada hermeneuta em particular, do passado e do presente, é um coletivista confesso, de esquerda ou de direita, e às vezes mudando de um coletivismo para outro de acordo com as realidades do poder. Karl Marx, Thorstein Veblen, Gustav von Schmoller (1838-1917) e a Escola Histórica Alemã são bem conhecidos. Em relação aos hermeneutas modernos, Martin Heidegger viu que era muito fácil tornar-se um nazista entusiasta depois que o regime nazista se estabeleceu. E Hans-Georg Gadamer não teve nenhuma dificuldade de adaptar-se ao regime nazista - em que era conhecido por ter somente uma "vaga simpatia" pelo Terceiro Reich - ou à ocupação soviética na Alemanha Oriental - onde, nas próprias palavras, conquistou "a estima especial das autoridades culturais da Rússia" por "cumprir fielmente as suas diretrizes, mesmo contra as próprias convicções"11.

\section{III - “AberturA" e Manter Viva A "Conversação"}

Aqui devemos notar duas variantes do tema hermenêutico comum. De um lado estão os relativistas e niilistas francos, que afirmam, com um fervor incoerentemente absolutista, que não há verdade. Eles aprovam o conhecido

\footnotetext{
${ }^{11}$ BARNES. A Kind of Integrity Review of Hans-Georg Gadamer. p. 12.
}

provérbio do anarquista epistemológico Paul Feyerabend (1924-1994) de que "vale tudo". Tudo. Tanto a astronomia quanto a astrologia têm a mesma validade ou invalidade. Uma possível virtude da doutrina do "vale tudo" é que, ao menos, qualquer um pode abandonar a empresa científica ou filosófica e ir pescar ou ficar bêbado. Essa virtude, contudo, é rejeitada pela corrente principal de hermeneutas, pois colocaria um fim em sua adorada e interminável "conversa". Resumindo, a corrente principal dos hermeneutas não gosta do provérbio "vale tudo" porque, em vez de anarquistas epistemológicos, são pestes epistemológicas. Insistem que, embora seja impossível chegar à verdade absoluta ou, com efeito, até mesmo entender outros teóricos ou cientistas, todos nós temos, ainda assim, uma profunda obrigação moral de participar de diálogos sem fim ou, como eles dizem, "conversas" para tentar chegar a alguma espécie de quase verdades transitórias. Para o hermeneuta, a verdade é a instabilidade do relativismo subjetivo, baseada em um "consenso" efêmero de mentes subjetivas que entram na conversa sem fim. Mas a pior coisa é que os hermeneutas afirmam que não há caminho objetivo, seja por observação empírica ou raciocínio lógico, que forneça algum critério para tal consenso. Visto que não há critérios racionais para um acordo, qualquer consenso é necessariamente arbitrário, baseado em sabe-se lá que capricho pessoal, carisma de um ou mais dos falantes ou, talvez, puro e simples poder e intimidação. Uma vez que não há critério, o consenso está sujeito à rápida e instantânea mudança, dependendo da mentalidade arbitrária dos participantes ou, certamente, de uma mudança nas pessoas que constituem a conversa eterna.

Um novo grupo de economistas hermeneutas, ávidos por encontrar alguns critérios para o consenso, se agarraram a uma frase de tipo Gestalt do economista Fritz Machlup (1902-1983), talvez usando o seu nome demasiadamente em vão. Eles chamam esse de critério de "princípio 'Arrá'!", querendo dizer que a verdade de uma proposição é baseada 
na exclamação "Arrá!" que a proposição pode suscitar no seio de alguém. Como dizem Don Lavoie (1951-2001) e Jack High: “Conhecemos uma boa explicação quando vemos uma e quando ela induz alguém a dizer 'arrá'"12. De alguma forma, não acho esse critério para verdade, ou mesmo para um consenso, muito convincente. Por exemplo, muitos de nós acharíamos a perspectiva de sermos confrontados com a opção de entrar em uma conversa sem fim e necessariamente infrutífera com pessoas incapazes de escrever uma frase clara ou de expressar um pensamento de modo claro como sendo o equivalente moral da peça Entre quatro paredes de Jean-Paul Sartre (1905-1980). Ademais, suspeito de que se alguém viesse com a proposição: "Seria ótimo dar a estes rapazes uma boa dose de realidade objetiva" ou se pelo menos batesse a porta para a conversa, isso conseguiria muitos "Arrás!" mais fervorosos do que as proposições obscuras dos próprios hermeneutas.

O mais importante dever moral proclamado pelos hermeneutas é que devemos a qualquer tempo manter viva a conversa. Uma vez que esse dever é implícito, ele nunca é defendido abertamente, e assim não conseguimos ser instruídos acerca do porquê de ser nossa obrigação moral manter um processo que produz resultados tão frágeis e efêmeros. Ao manter essa suposta virtude, os hermeneutas se encontram ardente e dogmaticamente opostos ao "dogmatismo" e proclamam a importância suprema de permanecerem infinitamente "abertos" a todos no diálogo. Hans-Georg Gadamer proclamou que o princípio mais elevado da filosofia hermenêutica é "manter-se aberto em uma conversa", o que significa sempre reconhecer "antecipadamente, a possível correção e mesmo a superioridade da posição do companheiro de conversa." Mas, como assinala Barnes, uma coisa é ser modestamente cético quanto à própria posição; outra, bastante distinta, é rejeitar qualquer outra posição como falsa ou

${ }^{12}$ LAVOIE, Don \& HIGH, Jack. Interpretation and the Costs of Formalism. (Unpublished Manuscript). p. 14. daninha. Jonathan Barnes salienta que o cético modesto

Reconhece que ele mesmo pode sempre estar errado. O filósofo "aberto" de Gadamer permite que o seu oponente possa sempre estar certo. Um cético modesto pode [...], com efeito, em seu modo modesto, considerar a história da filosofia como uma campanha incessante, marcada por derrotas frequentes e triunfos ocasionais contra as sempre poderosas forças da falácia e da falsidade. [...] Com alguns oponentes, ele não será "aberto": terá a mais absoluta certeza de que estão errados $^{13}$.

O filósofo hermenêutico mais importante nos Estados Unidos é Richard Rorty (1931-2007), que, em seu celebrado livro, Philosophy and the Mirror of Nature [A Filosofia e o Espelho da Natureza] $]^{14}$, dedica um espaço considerável à importância mais elevada de "manter a conversa". Em sua crítica brilhante de Rorty, Henry B. Veatch (1911-1999) mostra que, à questão principal sobre como nós, falantes, podemos alguma vez saber que ideais ou "postulados culturais" (na linguagem rortyana) são melhores do que outros, "Rorty pôde somente responder que, certamente, não pode haver uma coisa como conhecimento em relações a matérias desse tipo". Assim, se não há conhecimento e, daí, nenhum critério objetivo para chegar a posicionamentos, devemos concluir, nas palavres de Veatch, que "embora Aristóteles possa ter ensinado que 'a filosofia começa no maravilhar-se', [...] a filosofia hodierna pode somente terminar em uma permissividade totalmente conceitual ou intelectual"15. Resumindo,

${ }^{13}$ BARNES. A Kind of Integrity Review of Hans-Georg Gadamer. p. 13. Para uma crítica do triunfo da ideia de "abertura", ver: BLOOM, Allan. The Closing of the American Mind. New York: Simon and Schuster, 1987.

${ }^{14}$ RORTY, Richard. Philosophy and the Mirror of Nature. Princeton: Princeton University Press, 1979. [N. do E.: Em língua portuguesa a obra foi publicada na seguinte edição brasileira: RORTY, Richard. A Filosofia e o Espelho da Natureza. Trad. Antônio Trânsito. Rio de Janeiro: Relume Dumará, 1994].

15 VEATCH, Henry. Deconstruction in Philosophy: Has Rorty Made It the Denouement of Contemporary 
acabamos com o "vale tudo" de Paul Feyerabend ou, usando a admirável frase de Arthur Danto (1924-2013) em seu resumo de Friedrich Nietzsche (1844-1900), de que "tudo é possível"16. Ou, em uma palavra, "abertura" total.

Mas se todas as coisas são abertas e não há nenhum critério que leve os falantes a alguma conclusão, como tais decisões serão tomadas? Parece-me que, seguindo Veatch, essas decisões serão tomadas por aqueles com desejo de poder superior. E, assim, não é coincidência que hermeneutas de ponta se encontram flexíveis e "abertos" em resposta às rígidas demandas do poder estatal. Afinal, se Josef Stálin (1878-1953), Adolf Hitler (18891945) ou Pol Pot (1925-1998) entram no círculo "conversacional", não podem ser rejeitados sem mais nem menos, pois eles também podem oferecer um caminho superior para o consenso. Se nada é errado e todas as coisas são abertas, que mais podemos esperar? E, quem sabe, até mesmo esses governantes possam decidir, em uma explosão sardônica de "tolerância repressiva" marcuseana, manter algum tipo de "conversa" orwelliana em meio a um gulag universal.

Em todo este falatório sobre abertura, lembrei-me de uma aula dada pela professora Marjorie Hope Nicholson (1894-1981) na Columbia University, em 1942. Em uma crítica ao conceito de mente aberta, alertou: "Não deixem sua mente tão aberta de modo que tudo caia para fora".

Há um aspecto vantajoso para as exigências hermenêuticas em relação à abertura universal. Pois se nada - nenhuma opinião, nenhuma doutrina - pode ser imediatamente rejeitado como falso, daninho ou tagarelice tola, então também eles, nossos hermeneutas, devem ser poupados de tão rude rejeição. Manter a conversa a todo custo significa que

Analytical Philosophy? Review of Metaphysics, 39 (December 1985): p. 313-14, 316.

${ }^{16}$ DANTO, Arthur C. Nietzsche as Philosopher. New York: Columbia University Press, 1980, p. 12. Citado em: VEATCH. Deconstruction in Philosophy. p. 312. essas pessoas devem ser incluídas eternamente. E talvez esse seja o aspecto mais indelicado de todos.

Ademais, se alguém ler os hermeneutas, fica completamente claro que normalmente nenhuma sentença se segue de outra sentença. Em outras palavras, não somente o estilo é abominável, mas não há nenhum raciocínio que sustente as conclusões. Como a lógica e o raciocínio não são considerados válidos pelos hermeneutas, esse procedimento não é de surpreender. Em vez disso, pelo raciocínio os hermeneutas substituem dúzias ou vintenas de livros, que são citados, muito vagamente, em praticamente todos os parágrafos. Para apoiar as suas afirmações, os hermeneutas listarão repetidamente todo livro que possa possível ou remotamente estar relacionado com o tópico. Resumindo, o único argumento que possuem é o da autoridade, uma antiga falácia filosófica que parecem ter triunfalmente trazido de volta à vida. Pois, com efeito, se não há a verdade da realidade, se por lógica ou experiência devemos substituir consensos transitórios de caprichos subjetivos, sentimentos ou os jogos de poder dos vários falantes, então que mais há além de exibir o maior número possível de falantes como supostas autoridades ${ }^{17}$

Armados com o seu método especial, os hermeneutas são, portanto, capazes de rejeitar todos os ataques que vierem sobre eles, não importa o quão perceptivos ou penetrantes sejam, como "não acadêmico." Essa altiva refutação se origina de sua definição única para acadêmico, que para eles significa falatório pesado e obscurantista cercado por um matagal de citações vagas de livros e artigos que são irrelevantes em grande parte.

Assim, por que os renomados críticos da hermenêutica não jogaram o jogo no terreno dos próprios oponentes e, em vez disso, vagaram com dificuldade por montanhas e oceanos de asneiras, citando e refutando os hermeneutas ponto por ponto, artigo

\footnotetext{
${ }^{17}$ Devo este argumento a Sheldon Richman do Institute for Humane Studies (IHS) da George Mason University.
} 
acadêmico por artigo acadêmico? Fazer essa pergunta é praticamente respondê-la. $\mathrm{Na}$ verdade, fizemos essa pergunta a alguns dos críticos e eles responderam imediatamente, de um modo sincero, que não pretendem dedicar o resto de suas vidas vagando por esse miasma de conversa mole. Ademais, agir assim, jogar pelas regras dos próprios hermeneutas, seria conceder-lhes demasiada honra. O que insinuaria erroneamente que eles são, de fato, participantes dignos de nossa conversa. Em vez disso, o que eles merecem é o escárnio e a rejeição. Infelizmente, eles nem sempre recebem esse tratamento em um mundo no qual um número elevadíssimo de intelectuais parece ter perdido sua habilidade intrínseca de detectar disparates pretensiosos ${ }^{18}$.

\section{IV - Economia HeRmenÊUticA}

Os economistas gostam de pensar que a sua disciplina é "a mais difícil" das ciências sociais. Por isso, não é de surpreender que a hermenêutica - embora tenha conquistado o campo da Literatura e feito várias incursões de peso na Filosofia, no pensamento político e na História - tenha deixado uma marca muito pequena na Economia. Mas a disciplina da Economia anda em um estado de confusão metodológica por cerca de uma década, e

${ }^{18}$ Em um artigo espirituoso e perspicaz, o renomado filósofo Harry G. Frankfurt, da Yale University, chama este fenômeno de "porcaria" [bullshit], que, segundo afirma, é mais inimigo da verdade do que a mentira pura e simples, visto que um mentiroso reconhece que está violando a verdade, ao passo que o promotor de porcarias não o reconhece. Franfkurt escreve:

A proliferação contemporânea de porcaria também tem raízes mais profundas nas várias formas de ceticismo que negam a possibilidade de algum acesso confiável a uma realidade objetiva e que, portanto, rejeita a possibilidade de saber como as coisas verdadeiramente são. Essas doutrinas "antirrealistas" acabam com a confiança no valor dos esforços desinteressados para determinar o que é verdadeiro e o que é falso, e até mesmo na inteligibilidade da noção de investigação objetiva.

Ver: FRANKFURT, Harry G. On Bullshit. Raritan, 6 (Fall, 1986): p. 99-100. nessa situação crítica, metodologias menores, agora incluindo a hermenêutica, começaram a oferecer os seus serviços.

No exercício da economia, certamente, os profissionais nas trincheiras somente refletem de modo impreciso - ou, com efeito, mal têm interesse - no pequeno número de reflexões metodológicas que se encontram nos andares superiores da torre demarfim. Mas estas contemplações aparentemente filosóficas têm sim uma influência em longa duração na condução das teorias e direções da disciplina. Por aproximadamente duas décadas, o - com justiça - famoso The Nature and Significance of Economic Science [A Natureza e o Significado da Ciência Econômica] de Lionel Robbin (1898-1984) foi o trabalho metodológico orientador da profissão, apresentando uma versão diluída do método praxeológico de Ludwig von Mises (1881-1973). Robbins havia estudado no famoso Privatseminar de Mises em Viena, e a primeira edição da obra, lançada em 1932, enfatizou a Economia como uma disciplina dedutiva baseada nas implicações lógicas dos fatos universais da ação humana (por exemplo, que os seres humanos tentam atingir objetivos usando necessariamente meios escassos). $\mathrm{Na}$ segunda edição do livro de Robbin, publicada em 1935 e mais amplamente conhecida, a influência de Mises foi diluída um pouco mais, associada a sugestões de formalismo neoclássico diminutas que atingiriam a profissão por volta da época da Segunda Guerra Mundial ${ }^{19}$. Depois da guerra, a economia mais antiga foi inundada por uma emergente síntese neoclássica formalista e matemática das equações de Léon Walras (1834-1910), que cobrem a microeconomia, e da geometria de John Maynard Keynes (1883-1946), que se ocupa da macroeconomia.

Para ajudar e encorajar a conquista da economia pela nova síntese neoclássica surge o celebrado artigo de Milton Friedman (19122006) de 1953, "The Methodology of Positive Economics" [A Metodologia da Economia Positiva], que rapidamente se tornou unani-

19 ROBBINS, Lionel. An Essay on the Nature and Significance of Economic Science. London: Macmillan, [1932] 1935. 
midade, mandando, sem cerimônias, o livro The Nature and Significance of Economic Science de Robbin para a lixeira da história ${ }^{20}$. Por três décadas, seguro de si e sem adversários, o artigo de Friedman permaneceu praticamente o único retrato escrito da metodologia oficial para a economia moderna.

Deve notar-se que, como no triunfo da revolução keynesiana e muitas outras conquistas de várias escolas de Economia, o artigo de Friedman não ganhou os corações e mentes dos economistas no padrão do que podemos chamar de teoria whig da história da ciência, isto é, mediante uma refutação paciente de doutrinas rivais e predominantes. Como no caso da teoria de ciclo econômico de Ludwig von Mises e F. A. Hayek (18991992), predominante antes do Teoria Geral de Keynes, o livro de Robbins não foi refutado; foi simplesmente desconsiderado e esquecido. Aqui a teoria de Thomas Kuhn (1922-1996) dos paradigmas sucessivos é precisa na Sociologia ou processo do pensamento econômico, por mais deplorável que seja como uma prescrição para o desenvolvimento de uma ciência. Muito frequentemente, na Filosofia ou nas ciências sociais, as escolas de pensamento se sucederam como capricho ou moda, de modo muito semelhante ao modo pelo qual o estilo das bainhas das roupas das senhoras se sucederam. Certamente, tanto na Economia como em outras ciências da ação humana, forças mais sinistras, como política e ímpeto pelo poder, com frequência e de modo deliberado distorcem os caprichos da moda em seu favor.

$\mathrm{O}$ que Milton Friedman fez foi importar para a Economia a doutrina que tinha dominado a filosofia por cerca de uma década, a saber, o positivismo lógico. Ironicamente, Friedman importou o positivismo lógico mais ou menos na mesma época em que já tinha passado o auge, nos Estados Unidos, do férreo controle que exercia na profissão filosófica. Por três décadas, tivemos que aguentar a insistência

\footnotetext{
${ }^{20}$ FRIEDMAN, Milton. The Methodology of Positive Economics. In: Essays in Positive Economics. Chicago: University of Chicago Press, 1953.
}

esnobe na importância vital do teste empírico das deduções a partir das hipóteses como uma justificação para a prevalência dos modelos econométricos e de previsão, bem como uma desculpa universal para que a teoria fosse fundada em hipóteses reconhecidamente falsas e radicalmente irreais, uma vez que a teoria econômica neoclássica se sustenta claramente em asserções absurdamente irreais, tais como conhecimento perfeito, existência contínua de um equilíbrio geral sem lucros, sem perdas, sem incerteza, e ação humana sendo circundada pelo uso do cálculo que admite em um nível infinitesimal mudanças mínimas em nossas percepções e escolhas.

Resumindo, esse aparato formidável da teoria econômica neoclássica matematizada e dos modelos econométricos depende, em sua totalidade, do ponto de vista misesiano, do traiçoeiro terreno movediço de suposições falsas e até mesmo absurdas. A acusação austríaca de falsidade e de irrealidade, se é que percebida, foi grandiosamente rejeitada por sempre se remeter ao artigo de Friedman e pela afirmação de que a falsidade das suposições e premissas não têm importância, desde que a teoria "preveja" adequadamente. Em seus anos de fundação no início da década de trinta, a Sociedade Econométrica adornou seu brasão com o lema "Ciência é previsão", e essa era a essência da defesa da teoria neoclássica derivada de Friedman. Austríacos como Mises e Hayek retorquiram que as disciplinas da ação humana não são como as ciências físicas. Nos assuntos humanos, não há laboratórios onde as variáveis podem ser controladas e as teorias, testadas, pois (diferentemente das ciências físicas) não há quantitativos constantes em um mundo onde há consciência, livre arbítrio e liberdade de adotar valores e objetivos e, posteriormente, mudá-los. Essas disputas austríacas foram rejeitadas pelos neoclássicos, visto apresentarem um maior grau de dificuldade ao chegar às ciências humanas, e não eram algo que oferecesse uma diferença qualitativa perturbadora.

A síntese neoclássica, contudo, começou, no início da década de 1970, a perder o seu 
poder de entender ou de predizer o que estava acontecendo na economia. A recessão inflacionária que apareceu pela primeira vez de modo dramático entre 1973 e 1974 colocou um fim em uma hegemonia, arrogante e inquestionável, de trinta e cinco anos da ala keynesiana da síntese neoclássica, pois a teoria keynesiana e a política se sustentavam na hipótese crucial de que a recessão inflacionária simplesmente não poderia acontecer. Naquele momento, o monetarismo de Friedman tomou a dianteira, mas o monetarismo caiu do cavalo depois de fazer uma série de previsões desastrosamente erradas desde o começo da era Reagan até o presente. Mas aquele que vive de previsões está destinado a morrer de previsões.

Além dessas falhas do keynesianismo e do monetarismo, os enganos e erros da previsão econométrica se tornaram muito notórios para que fossem ignorados, e uma profissão rica e extremamente arrogante, sempre usando computadores de alta velocidade, parece gozar cada vez menos de habilidade para prever até mesmo o futuro imediato. Mesmo os governos, apesar de atenção assídua e ajuda de economistas e previsores neoclássicos de ponta, parecem ter grande dificuldade em prever o seu próprio gasto, muito menos do que as suas próprias receitas, sem falar das receitas ou dos gastos de terceiros.

Entre essas falhas, houve um desgaste gradual do formalismo clássico da microeconomia de Walras que às vezes era provocado por líderes desiludidos que operam de dentro deste paradigma dominante.

Como resultados desses problemas e falhas, os últimos dez ou quinze anos assistiram ao desenvolvimento da "situação crítica" de Kuhn no campo da Economia. Quando a ortodoxia neoclássica começa a desmoronar, surgem os paradigmas rivais. Animada também pelo prêmio Nobel concedido a Hayek em 1974, a Economia Austríaca ou misesiana gozou de um renascimento desde então, com inúmeros austríacos ensinando em faculdades nos Estados Unidos e na Grã-Bretanha. Recentemente, emergiram cinco ou seis programas de graduação ou centros austríacos nos Estados Unidos.

Em uma situação crítica, certamente, o mau empurra o bom para a nova atmosfera de diversidade epistemológica e substantiva. Ninguém nunca conseguiu garantir que, se uma centena de flores haveria de florescer, todas estariam em boas condições. $\mathrm{Na}$ esquerda, a não teoria do institucionalismo teve um relance de retorno, empurrada pelos "pós-keynesianos" - inspirados por Joan Robinson (1903-1983) - e neomarxistas "humanistas" que substituíram uma vaga adesão à "descentralização" e à proteção de todas as formas de vida animal e vegetal pelos rigores da teoria do valor-trabalho.

E isso nos leva de volta à hermenêutica. Pois nesse tipo de atmosfera, até mesmo o submundo da hermenêutica disputará o seu pedaço ao sol. Talvez o economista hermenêutico mais proeminente nos Estados Unidos seja Donald N. McCloskey ${ }^{21}$, que denomina o seu ponto de vista de "retórico" e cujo ataque à verdade ocorre em nome da retórica e da eterna conversa hermenêutica ${ }^{22}$. McCloskey, infelizmente, segue a trilha moderna da corrida retórica, emporcalhada e divorciada de uma âncora firmada na verdade, ignorando a tradição aristotélica da "retórica nobre" como meio mais eficiente de persuadir as pessoas das proposições corretas e verdadeiras ${ }^{23}$. Para

${ }^{21}$ A partir de 1995, quando já estava com 53 anos de idade, o professor Donald N. McCloskey, após uma cirurgia para mudança de sexo, passou a adotar a identidade de professora Deirdre N. McCloskey, como é mais conhecido atualmente. (N. do E.)

${ }^{22}$ McCLOSKEY, Donald N. The Rhetoric of Economics. Madison: University of Wisconsin Press, 1985. Para uma crítica misesiana completa do trabalho de McCloskey, veja a seguinte resenha do livro: HOPPE, Hans-Hermann. In Defense of Extreme Rationalism: Thoughts on Donald McCloskey's The Rhetoric of Economics. Review of Austrian Economics, 3 (1989): p. 179-214.

${ }^{23}$ Ver: WEAVER, Richard M. The Ethics of Rhetoric. Chicago: University of Chicago Press, 1953; ARNHART, Larry. Aristotle on Political Reasoning: A Commentary on The Rhetoric. DeKalb: Northern Illinois University Press, 1981. 
os aristotélicos, é somente a retórica de "base" que é divorciada dos princípios verdadeiros. McCloskey está agora organizando um centro para estudos retóricos na Universidade de Iowa, que organizará volumes sobre retórica em um número de diversas disciplinas.

Por mais que reprove a hermenêutica, tenho certa simpatia em relação a McCloskey, um historiador da economia que enfrentou anos como instrutor militar e chefe de esquadrão nos ranques positivistas da Escola de Chicago, cujos principais expoentes são Milton Friedman e George Stigler (1911-1991). McCloskey está reagindo contra décadas dessa hegemonia positivista arrogante, de um pretenso "teste" da teoria econômica que realmente nunca acontece e de altivas declarações de positivistas como "Eu não entendo o que você quer dizer", quando eles (ó céus!) sabem bem o que você quer dizer, mas discordam, e usam os próprios critérios limitados de significado para rejeitar o seu argumento. Deste modo, os positivistas, por um longo tempo, foram capazes de deixar de lado praticamente todas as questões filosóficas importantes e consigná-las aos desprezados departamentos de religião e belles lettres. De certo modo, o surgimento da hermenêutica é a vingança daqueles departamentos, respondendo aos positivistas que se "ciência" é somente o quantitativo e o "testável", então lhes atolaremos em um negócio que é verdadeiramente sem sentido.

É mais difícil desculpar o caminho traçado pelo grupo principal de hermeneutas na Economia, um grupo de austríacos renegados e de ex-misesianos reunidos no Center for Market Processes [Centro de Processos de Mercado] da George Mason University. O líder espiritual desse pequeno grupo, Don Lavoie, atingiu o ápice ao ter a sua foto estampada em sua revista Market Process conversando com o grande Gadamer ${ }^{24}$. Lavoie organizou uma Society of Interpretive Economics [Sociedade de Economia Interpretativa] (interpretação é uma senha para hermenêutica) para difundir o novo evangelho e tem a desfaçatez

${ }^{24}$ Market Process, 4 (Fall, 1986): p. 16. de entregar um trabalho intitulado "Mises and Gadamer on Theory and History" [Mises e Gadamer sobre Teoria e História], que, como sugeriu um colega meu, é o equivalente moral de um escrito meu que se chamasse: "Lavoie e Hitler sobre a Natureza da Liberdade".

Deve notar-se que o niilismo tinha escoado para o pensamento austríaco atual antes de Lavoie e seus colegas no Center for Market Processes o terem abraçado com tanto entusiasmo. Começou quando Ludwig $\mathrm{M}$. Lachmann (1906-1990), que havia sido um discípulo de Hayek na Inglaterra nos anos trinta e que tinha escrito uma obra austríaca competente intitulada Capital and Its Structure [O Capital e a sua Estrutura] na década de cinquenta, foi subitamente convertido pela metodologia do economista inglês G. L. S. Shackle (1903-1992) durante a década de sessenta ${ }^{25}$. Desde meados da década de setenta, Lachmann, lecionando parte de todos os anos na New York University, entrou em uma cruzada para trazer as bênçãos da aleatoriedade e do abandono de teoria para a Economia Austríaca. Quando Lavoie e seus colegas descobriram Heidegger e Gadamer, Lachmann abraçou o novo credo na primeira conferência anual de 1986 (e, se estivermos com sorte, a última anual) da Society of Interpretive Economics da George Mason University. O credo misesiano genuíno, entretanto, ainda floresce no Ludwig von Mises Institute na Auburn University e em suas publicações The Free Market, Mises Review e Quarterly Journal of Austrian Economics, que em sua primeira edição incluiu uma crítica do livro quase hermenêutico de dois ex-misesianos que alegam ter descoberto o segredo da economia nos trabalhos de Henri Bergson (1859-1941) ${ }^{26}$.

${ }^{25}$ LACHMANN, Ludwig M. Capital and Its Structure. London: London School of Economics, 1956. O Lachmann posterior, pós-schakeliano ou niilista, pode ser encontrado em: LACHMANN, Ludwig M. From Mises to Shackle: An Essay on Austrian Economics and the Kaleidic Society. Journal of Economic Literature, 54 (1976).

${ }^{26}$ Ver: BAIRD, Charles W. The Economics of Time and Ignorance: A Review. Review of Austrian Economics, 1 (1987): p. 189-223. 
Uma das principais motivações dos hermeneutas ex-misesianos é que o horror deles pela Matemática, diante da qual reagem como se estivessem diante da Medusa, os leva a abraçar praticamente qualquer aliado em sua luta contra o positivismo e o formalismo neoclássico. E, assim, descobrem que, - oh! - os institucionalistas, os marxistas e os hermeneutas também usam muito pouco a Matemática. Mas antes de abraçarem totalmente o credo desesperado de que o inimigo do meu inimigo é necessariamente o meu amigo, nossos hermeneutas do Processo de Mercado deveriam ser avisados de que pode haver coisas piores nesse mundo do que matemática ou até mesmo do que positivismo. $\mathrm{E}$, em segundo lugar, além do nazismo ou do marxismo, uma destas coisas pode ser a hermenêutica.

E assim como a história do professor McCloskey pode servir como uma mitigação parcial de sua adoção da hermenêutica, podemos retroceder ainda mais e mitigar os pecados dos positivistas lógicos. Pois, afinal, os positivistas, por mais relutantes que sejam em admiti-lo, também desceram sobre nós do Olimpo. Eles cresceram na velha Viena e se acharam em um mundo germânico dominado por credos proto-hermenêuticos como o hegelianismo e os do jovem Heidegger que naquela altura estava deixando a sua marca. Depois de ler e de ouvir a dialética e a proto-hermenêutica dia sim, dia não e de ter mergulhado por anos na insensatez que lhes disseram constituir a filosofia, é de estranhar que eles - incluindo para nossos propósitos Karl Popper bem como Rudolf Carnap (1891-1970), Hans Reichenbach (1891-1953), Moritz Schlick (1882-1936) e outros - acabariam por atacar e exclamar que a coisa toda era sem sentido ou que eles pediriam aos gritos precisão e clareza na linguagem? É de surpreender que os positivistas nascentes, como McCloskey meio século depois, iriam tão longe a ponto de jogar fora o bebê filosófico com a água neo-hegeliana?

$\mathrm{Na}$ peroração ao seu panegírico à economia hermenêutica, o ex-misesiano Richard Ebeling proclama: "O homem ama falar sobre si mesmo"27. Mas, em sentido contrário, destaco as sábias palavras do norte-americano Tom Lehrer, satirista político e cultural. Na década de 1960, Lehrer percebeu que "muitas pessoas se lamentam sobre sua 'inabilidade de comunicar-se'". Lehrer acrescentou: "Parece-me que se você não tem capacidade de comunicar-se, o mínimo que você pode fazer é calar-se". E isso é algo que, infelizmente, Ebeling e seus colegas hermenêuticos ainda não aprenderam a fazer. cos

27 EBELING, Richard M. Hermeneutics and the Interpretive Element in the Analysis of the Market Process. Center for Market Processes Working Paper. Fairfax: Department of Economics, George Mason University, 1985. p. 45. Ver, também: FRANKFURT. On Bullshit. p. 100. 